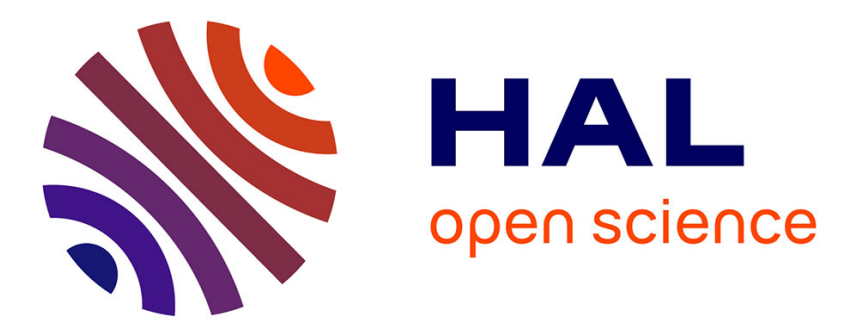

\title{
Influence of hydration/dehydration on adsorbed molecules: Case of phthalate on goethite
}

\author{
R. Botella,; Chiter,; Costa, ; Nakashima,; Lefèvre
}

\section{To cite this version:}

R. Botella,; Chiter,; Costa,; Nakashima,; Lefèvre. Influence of hydration/dehydration on adsorbed molecules: Case of phthalate on goethite. Colloids and Surfaces A: Physicochemical and Engineering Aspects, 2021, 625, pp.126872. 10.1016/j.colsurfa.2021.126872 . hal-03379548

\section{HAL Id: hal-03379548 \\ https://hal.science/hal-03379548}

Submitted on 15 Oct 2021

HAL is a multi-disciplinary open access archive for the deposit and dissemination of scientific research documents, whether they are published or not. The documents may come from teaching and research institutions in France or abroad, or from public or private research centers.
L'archive ouverte pluridisciplinaire HAL, est destinée au dépôt et à la diffusion de documents scientifiques de niveau recherche, publiés ou non, émanant des établissements d'enseignement et de recherche français ou étrangers, des laboratoires publics ou privés. 
Influence of hydration/dehydration on adsorbed molecules: Case of phthalate on goethite.

Botella, R. ${ }^{1,2}$; Chiter, F. ${ }^{1}$; Costa, D. ${ }^{1}$; Nakashima, S. ${ }^{2,3,4}$; Lefèvre, G. ${ }^{1, *}$

${ }^{1}$ PSL Research University, Chimie ParisTech-CNRS, Institut de Recherche de Chimie Paris, 11 rue Pierre et Marie Curie, F-75005 Paris, France

${ }^{2}$ Department of Earth and Space Science, Graduate School of Science, Osaka University, Machikaneyama-cho 1-1, Toyonaka-shi, Osaka 560-0043, Japan

${ }^{3}$ Research Institute for Natural Environment, Science and Technology (RINEST), Tarumi-cho 3-6-32 Maison Esaka 1F, Suita-shi, Osaka 564-0062, Japan ${ }^{4}$ Faculty of Environmental and Urban Engineering, Kansai University, Yamate-cho 3-3-35, Suita-shi, Osaka 564-8680, Japan

* corresponding author: gregory.lefevre@ chimieparistech.psl.eu

\begin{abstract}
:
The behavior of adsorbed species on metal (hydr)oxides under water unsaturated conditions has been seldom studied despite its major implications in several domains such as geochemistry and heterogeneous catalysis. In this study, chemical forms of phthalate adsorbed on iron hydroxide (goethite) were investigated by infrared spectroscopy upon hydration and dehydration of goethite particle aggregates. Experimental results indicated important changes with relative humidity (RH) on chemical forms of phthalates adsorbed on goethite. With increasing RH from the dried state, bidentate phthalate surface complex is partially desorbed to form a protonated monodentate phthalate complex by using protons from water molecules. This protonated monodentate phthalate is still kept adsorbed on the goethite surface but becomes deprotonated at high $\mathrm{RH}$ values by solvating in liquid-like water covering on the goethite surface. DFT calculations made on a simplified system support these adsorption models. These results indicate that further studies are needed on the behavior of adsorbate in water unsaturated systems including hydration/dehydration processes.
\end{abstract}

Keywords: phthalate, goethite, infrared, DFT calculations, hydration, dehydration, adsorption, desorption 


\section{Introduction}

Wetting/drying transitions are found in many systems both environmental [1] and surface and material chemistry $[2,3]$. Thus, the speciation of adsorbates on several metal (hydr)oxides substrates has been studied for decades. For example, the solid/solution interfaces where the adsorption of different organic pollutants on iron hydroxides [4,5] and aluminum hydroxides [6,7] has been studied. At the interface solid/vapor or solid/gas, organic molecules can be used as acid-base probes [8,9], or in the context of catalysis, as reactive compounds $[10,11]$.

Amongst the analytical methods to determine the speciation of adsorbates, infrared spectroscopy is the most versatile and was used extensively at both interfaces (solid/solution and solid/gas). In the case of organic molecules, this technique allows to identify the chemical groups in interaction with the surface [12], in the presence of a solvent like water, or at the solid/gas interface, and to estimate the strength of the interaction, and so, the geometry of the surface complex [13]. The interactions between carboxylic (carboxylate) groups and hydrated metal (hydr)oxides surfaces are especially well documented [14-19]. Adsorption is mainly ascertained by the study of symmetric and asymmetric stretching of the $\mathrm{COO}^{-}$moieties (absorption bands around $1350-1450 \mathrm{~cm}^{-1}$ and $1500-1600$ $\mathrm{cm}^{-1}$, respectively).

In the case of the study of wetting/drying transitions, infrared spectroscopy has the significant advantage to be able to probe the solvent (water) with a high sensitivity. Moreover, it allows to determine the environment of the water molecules and the structure of the phase. Thus, infrared analysis of water vapor on a surface has shown two kinds of water molecules: the first type is closer to the surface and is called ice-like water because of its spectral features reminding those of ice (stretching around $3200 \mathrm{~cm}^{-1}$ ) $[20,21]$ but existing at ambient temperature, and another one more conventional " liquid-like" close to bulk water (stretching around $3400 \mathrm{~cm}^{-1}$ ). Thus, these water species are indicators of the thickness of the water film at the surface and these characteristic bands of water allow to quantify, in an in situ and real-time manner, the wetting/drying evolution.

The drying of solids without adsorbate has been studied by infrared spectroscopy and has provided interesting results regarding the way water molecules organize themselves and their reactivity on a surface under unsaturated conditions [21, 22]. In the presence of dissolved species, several phenomena have been observed. For instance, the surface polymerization of silicic acid on ferrihydrite has been shown [23]. The impact of drying has also been studied for sulfate ions on iron (hydr)oxides [24-27], but without detailing the evolution of the surface speciation during the drying process (only the comparison between solid/solution and dried interfaces has been done). Other works have been performed on the drying behavior of diacids on both goethite [28] and clay minerals [29] with the same approach limited to the two different interfaces. In all those studies, infrared spectroscopy was the main technique to determine the speciation of the adsorbates. A solid/vapor system has also been investigated, focused on the gaseous formic acid adsorption on clays at decreasing relative humidity (RH) [30]. However, further studies are necessary by using more complex adsorbate including solid/water interfaces.

Few studies have been published on the effect of drying on the speciation of adsorbate, and even less on the behavior of these molecules while going through the different stages of hydration including the thin water film covering on the substrate [21]. Moreover, more rigid adsorbates, such as aromatic cycle containing phthalate molecule, have not been studied with respect to the change of relative humidity. Phthalates are soil pollutants $[31,32]$ with chronic toxicity used as solvent, additives and plasticizers in daily life. It is also a simplified model compound representing chemical functionalities of natural organic matter (NOM) in aquatic and soil environments [33-35].

In this work, the behavior of the phthalate ions adsorbed onto goethite $(\alpha-\mathrm{FeOOH})$, during a drying/wetting cycle has been investigated. Goethite has been chosen because it is a well-known model for soil adsorption with a good chemical stability. Infrared micro-spectroscopy was the main analytical technique, associated with a Quartz Crystal Microbalance (QCM). Moreover, to support interpretation of results observed at low relative humidity, DFT periodical calculations have been performed on the system to see the surface reaction evolution with the number of adsorbed water added one by one. 


\section{Materials and Methods}

\section{Goethite}

Goethite samples were prepared after the methods of Schwertmann and Cornell [36] and Otsuka and Nakashima [37]. While they used $\mathrm{Fe}\left(\mathrm{NO}_{3}\right)_{3}$ and $\mathrm{KOH}$ in the methods, we used $\mathrm{FeCl}_{3}$ and $\mathrm{NaOH}$ for avoiding remaining nitrate adsorbed on goethite surfaces and for possible future comparison with different ionic strength conditions.

$100 \mathrm{~mL}$ of $0.1 \mathrm{~mol} . \mathrm{L}^{-1} \mathrm{FeCl}_{3}$ solution and $180 \mathrm{~mL}$ of $5 \mathrm{~mol} . \mathrm{L}^{-1} \mathrm{NaOH}$ solution were mixed and diluted to $2 \mathrm{~L}$ with pure water (MilliQ: Electrical resistivity $>18.2 \mathrm{M} \Omega \mathrm{cm}$ ). This suspension with rapid precipitation of brownish suspension was subdivided into two polypropylene vessels $(1 \mathrm{~L}$ each) and incubated at $70{ }^{\circ} \mathrm{C}$ for 60 hours. Then yellowish-brown precipitates were filtered using $0.2 \mu \mathrm{m}$ Millipore filter. They were washed by pure water three times and dried in an electric oven at $50{ }^{\circ} \mathrm{C}$ for 4.5 hours.

The obtained precipitate was characterized by visible, Raman and infrared (IR) microspectroscopy, indicating that it was composed of goethite. X-ray diffraction pattern of the iron hydroxide showed six dominant peaks at $2 \theta=21,3^{\circ}, 26,4^{\circ}, 33,2^{\circ}, 34,7^{\circ}, 36,7^{\circ}, 39,2^{\circ} 40,1^{\circ}$ and $41,3^{\circ}$, corresponding to reported peaks of goethite [36]. The BET surface area measured on a sample from another batch was $29.2 \mathrm{~m}^{2} \cdot \mathrm{g}^{-1}$ [38] and its point of zero charge (PZC) is 8.6 by surface titration. Its surface charge at $\mathrm{pH} 6$ was about +0.04 and $+0.05 \mathrm{mmol} / \mathrm{g}$ for ionic strength of $\mathrm{I}=0.01$ and 0.1 , respectively. The morphology of goethite particles characterized by Laser Scanning Confocal Microscopy in a previous work showed that they are randomly oriented aggregates of a few hundred $\mathrm{nm}$ with some larger aggregates of a few micrometers [39].

\section{Phthalate}

Phthalic acid powder (Wako chemicals, 163-02462, Lot PKE1851) was dissolved in pure water to obtain $10 \mathrm{~mL}$ of $9.05 \mathrm{mM}$ aqueous solution.

\section{Phthalate-goethite suspension}

In order to prepare phthalate adsorption on goethite, $1.125 \mathrm{~g} . \mathrm{L}^{-1}$ of aqueous suspension of powdered goethite with $0.1 \mathrm{M} \mathrm{NaCl}$ was first prepared. Then $5.52 \mu \mathrm{L}$ of the phthalic acid solution (corresponding to $50 \mathrm{nmol}$ ) was added to $1 \mathrm{~mL}$ of the goethite aqueous suspension. The mixture was stirred during 24 hours by a magnetic stirrer to obtain adsorption equilibrium. Two duplicates were prepared: one for $\mathrm{pH}$ measurement and another for IR measurements. $\mathrm{pH}$ values were measured at the initial and final states during the 24 hours stirring: $\mathrm{pH}$ was initially 5.9 and after 24 hours stirring, it was 6.1. This $\mathrm{pH}$ value is close to natural water $\mathrm{pH}$ (between 6 and 8) and is expected to change upon dehydration procedure.

\section{Relative Humidity Control System}

For infrared (IR) measurements of phthalate-goethite mixtures during wetting/drying cycles, a plastic humidity control cell $(36 \times 36 \times 14 \mathrm{~mm})$ with a $\mathrm{CaF}_{2}$ window $(20 \mathrm{~mm}$ diameter) was fabricated (Figure 1). The RH of the cell interior was controlled by flowing a mixture of dry air and watersaturated air with varying proportions. The dry air was provided from a dehumidifier (Jasco, AM-12) through a digital flow meter (KOFLOC, D8500). The water-saturated air was made by flowing the same dry air via another digital flow meter through two bottles of pure water (Milli-Q, Electrical resistivity $>18.2 \mathrm{M} \Omega \mathrm{cm}$ ). The humidity and temperature in the cell were monitored every second by a small temperature and humidity sensor (SENSIRION, SHT 35 with a membrane filter) equipped with a data logger (Syscom, SCHM-1) connected to a PC with a USB cable. The humidity was increased from about $0.0 \%$ to $78 \%$ by changing the flow rates of humid and dry air by two flow meters at a total flow rate of about 1 L. $\mathrm{min}^{-1}$. 


\section{a) IR/RH/QCM system}

\section{Quartz Crystal Microbalance}

In order to study effects of the wetting/drying cycle on phthalate-goethite mixtures, the relative humidity control system combined with IR micro-spectroscopy and quartz crystal microbalance developed by Kudo et al. [40,41] was used (Figure 1).

A QCM system (SEIKO EG\&G, QCM922A) was used in this study for measuring weights of adsorbed water on the phthalate-goethite mixtures placed on a gold electrode coating on an AT-cut quartz of QCM sensor (SEIKO EG\&G, QA-A9MAU(M)(SEP)) in a plastic container. Changes in resonant frequency of quartz from the initial value $\left(F_{0}\right)$ around $9.0 \mathrm{MHz}$ were monitored at every second when water was adsorbed under various relative humidity. These frequency changes can be converted to mass changes for the present system [40,41].
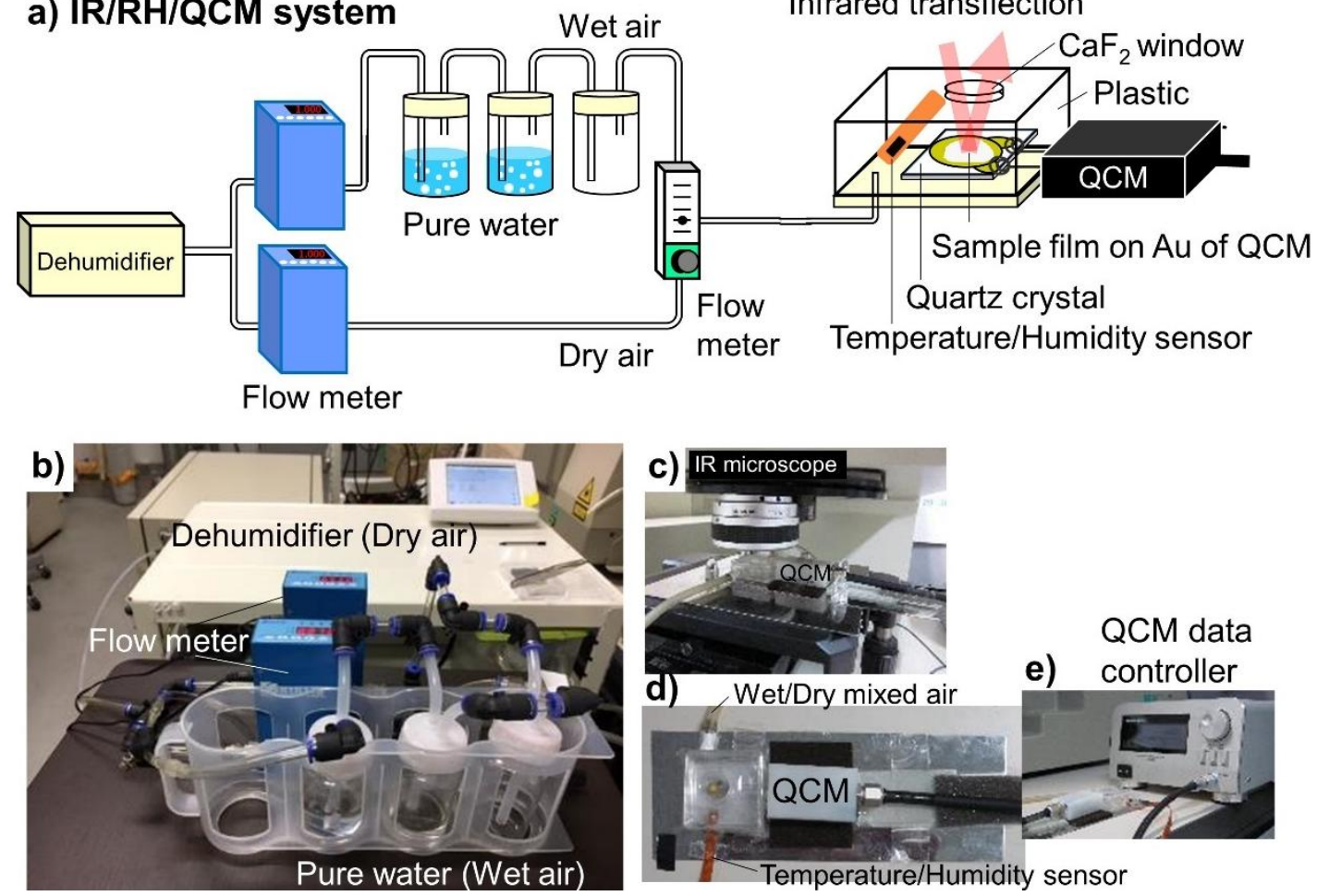

Figure 1. Infrared (IR) microspectroscopy combined with relative humidity (RH) control system and quartz crystal microbalance (QCM): (a) schematic image of the system, (b) photograph of the RH control system, (c) photograph of the RH control cell under an IR microscope, (d) close-up photograph of the RH control cell with QCM, and (e) QCM data controller.

\section{Preparation of phthalate-goethite particle aggregats}

One drop $(5 \mu \mathrm{L})$ of the phthalate-goethite mixture suspension was placed with a micropipette on the Au electrode coating on an AT-cut quartz of the QCM in a plastic container (Figure 1). Dried air was flowed in the plastic container with a flow rate of more than $1 \mathrm{~L} \cdot \mathrm{min}^{-1}$ for about 30 to $45 \mathrm{~min}$. The dried phthalate-goethite deposit is expected to have a weight of about $5.625 \mu \mathrm{g}$ of goethite plus about $7.4 \mathrm{ng}$ of phthalate. As a reference, the goethite only system was also prepared, following the procedure described above, using a suspension of goethite without phthalate.

\section{Infrared Microspectroscopy}

In order to evaluate changes in infrared (IR) spectra of the phthalate-goethite deposit, IR transflection (transmission-reflection) spectra of the deposit on the Au electrode on QCM quartz 
crystal were measured under different $\mathrm{RH}(0.0-77 \%)$. The phthalate-goethite deposit on the QCM in the plastic cell with a $\mathrm{CaF}_{2}$ window was placed under a Fourier transform IR spectroscopy (FT-IR) microscope (Jasco IRT30+FTIR680: a Cassegrain objective mirror with a magnification of 16, MCT detector, ceramic IR source, and $\mathrm{KBr}$ beam splitter) (Figure 1). The environment outside the RH cell was the ambient experimental room with normal air conditioning with the temperature around $28^{\circ} \mathrm{C}$ and RH of about $60 \%$.

A background reflection spectrum was measured on the Au-coated quartz crystal without any sample using an aperture size of $100 \times 100 \mu^{2}$ and then a sample transflection spectrum was measured on the deposit with the same aperture. All the spectra were obtained by accumulating 64 scans at a wavenumber resolution of $4 \mathrm{~cm}^{-1}$. RH and temperature were monitored every second and were averaged for 60 seconds, corresponding to the time needed to record the IR spectrum. These transflection spectra were obtained in absorbance, and the band areas were measured after baseline correction at each stable RH value. Every experiment was made in triplicate giving similar results.

\section{Computational methods}

The total energy calculations were performed within the density functional theory (DFT) and the generalized gradient Pedrew-Burke-Erzenhoff (PBE) exchange correlation functional was used for the whole study [42]. To solve the Kohn-Sham equations we use the Vienna Ab initio Simulation Package (VASP version 5.4.1) [43,44]. VASP performs an iterative diagonalization of the KohnSham hamiltonian via unconstrained band-by-band minimization of the norm of the residual vector to each eigenstate and via optimized charge density mixing routines. A smearing of $0.03 \mathrm{eV}$ was used. In the literature [45, 46, 47], cut-off of 500, 800 or $400 \mathrm{eV}$ have been chosen. Because we wanted to explore many configurations, we excluded the $800 \mathrm{eV}$ cut-off. A test of convergence of energy with the value of the cut-off was performed. We concluded that $400 \mathrm{eV}$ was already a value where the energy was converged. We used an energy cut-off of $400 \mathrm{eV}$ for total energy calculations. The electronic optimizations were done up to a convergence of $10^{-4} \mathrm{eV}$ for the self-consistent loop and until all forces on the atoms were lower than $0.02 \mathrm{eV} . \AA^{-1}$ for the geometry relaxations.

Bulk goethite and its surfaces are routinely modelled with periodic density functional theory (DFT)[47-49] including an on-site Coulomb repulsion term U (GGA + U) [46,50]. The (GGA + U) was used in order to describe the strong correlation effects of the oxide. Several $U$ values were compared and the final values $(\mathrm{H}=6, \mathrm{~J}=1)$ were chosen to give the best agreement with the cell parameters. For bulk $\mathrm{FeOOH}$, the magnetic moment of the iron atoms was set at a starting point at the experimental value, in the AFM order (++/--), and the optimized values were between 3.9 and 4.1, so in agreement with experimental data and other theoretical calculations. The Van der Waals corrections are calculated with DFT-D2 method of Grimme [50]. Furthermore, we applied dipole corrections along the $z$ axis, when calculating the adsorption energies (vide infra), since in our model the adsorbate interacts only on one side of the slab.

Bulk goethite was considered in the Pbnm symmetry. The optimized cell parameters of bulk goethite are $4.67 \times 10.1 \times 3.07 \AA$, in agreement with the experimental value of $4.63 \times 9.96 \times 3.02 \AA$ [46] and other theoretical works [46,47]. The $\mathrm{K}$ points grid was optimized and to model the bulk, a $\mathrm{K}$ points grid ( $3 \times 2 \times 4)$ in the $a, b$ and $c$ directions, respectively, was used. The (001) surface contains four layers. The three bottom layers were kept frozen. After the great number of configurations tested, the calculations were performed at the $\Gamma$-point. Open shell calculations were performed. We found that the Fe magnetic moments were between 3.9 and 4.1, whatever the Fe location (surface bulk) and the nature of the ligand (phthalate or water). Surface goethite $\mathrm{FeOOH}(001)$ hydration/hydroxylation was performed by saturating the surface iron atoms with 3 water molecules, thus recovering the bulk octahedral Fe coordination. Although (001) facets are not the major surfaces exposed in goethite nanoparticles, they are among the most reactive surface forming the most stable surface complexes. The results on such a surface are expected to provide the existence of this mechanism on other facets.

We calculated the adsorption energy $\left(\Delta \mathrm{E}_{\mathrm{ads}}\right)$ according to the following equation:

$$
\Delta \mathrm{E}_{\mathrm{ads}}=E_{\text {molecule }+ \text { slab }}-E_{\text {molecule }}-E_{\text {slab }}
$$


where $E_{\text {moleculetslab }}$ is the total energy of the optimized structure formed after the phthalate (or water) molecule is (chemically) absorbed on the goethite slab and $E_{\text {molecule }}$ and $E_{\text {slab }}$ are the total energies of the non-interacting phthalic acid (or water) molecule and the slab, respectively. The adsorption of the molecule may be in the intact form, or in the dissociated form. In the latter case, one proton (for adsorbed water) or two protons (for adsorbed phthalate) are adsorbed on a vicinal surface $\mathrm{O}$ atom.

For the addition of $n$ water molecules on the previously adsorbed phthalate ion, the adsorption energy is:

$$
\Delta E_{\text {addition }}=E n_{H 2 O+\text { slab-phtalate }}-n E_{H 2 O}-E_{\text {slab-phtalate }}
$$

\section{Results}

\section{IR characterization of the goethite only system}

For the goethite only system RH was changed from 0.0 up to $77 \%$ and then down to $0.0 \%$ (Table 1). The RH value became stable within 15 minutes, so after keeping the same RH values for about 15 minutes it has been increased or decreased (Table 1).

Table 1. Time, temperature, relative humidity $(\mathrm{RH})$, frequency shift $(\Delta \mathrm{F})$, mass changes $(\Delta \mathrm{m})$, and total $\mathrm{OH}$ band area during wetting/drying processes of a goethite particle aggregates. "_ " correspond to the points where the frequency shows a complex behavior.

\begin{tabular}{cccccc}
\hline $\begin{array}{c}\text { Time } \\
(\mathrm{min})\end{array}$ & $\begin{array}{c}\text { Temp } \\
\left({ }^{\circ} \mathrm{C}\right)\end{array}$ & $\begin{array}{c}\mathrm{RH} \\
(\%)\end{array}$ & $\begin{array}{c}\Delta \mathrm{F} \\
(\mathrm{Hz})\end{array}$ & $\begin{array}{c}\Delta \mathrm{m} \\
(\mu \mathrm{g})\end{array}$ & $\begin{array}{c}\text { Total } \mathrm{OH} \\
\text { Band area }\end{array}$ \\
\hline 0 & 29.8 & 0.0 & 0 & 0 & 0.00 \\
15 & 29.5 & 0.0 & -120 & 0.13 & 0.03 \\
30 & 29.4 & 9.8 & -337 & 0.36 & 2.05 \\
45 & 29.4 & 20.7 & -385 & 0.42 & 4.12 \\
60 & 29.3 & 30.4 & -572 & 0.62 & 6.45 \\
75 & 29.3 & 39.8 & -701 & 0.76 & 7.68 \\
90 & 29.2 & 49.3 & -832 & 0.90 & 10.10 \\
105 & 29.1 & 58.2 & -923 & 1.00 & 15.61 \\
120 & 29.1 & 67.8 & 2460 & -2.67 & 27.21 \\
135 & 29.0 & 74.9 & - & - & 92.06 \\
150 & 29.0 & 75.3 & - & - & 91.54 \\
165 & 29.1 & 74.5 & - & - & 86.00 \\
180 & 29.0 & 77.3 & - & - & 293.89 \\
195 & 29.0 & 74.1 & 131 & -0.14 & 183.72 \\
210 & 29.0 & 67.3 & 95 & -0.10 & 41.84 \\
225 & 29.0 & 59.8 & 131 & -0.14 & 20.25 \\
240 & 28.9 & 51.4 & 260 & -0.28 & 15.65 \\
255 & 28.9 & 43.1 & 368 & -0.40 & 11.62 \\
270 & 28.9 & 33.9 & 604 & -0.65 & 7.93 \\
285 & 29.0 & 24.6 & 380 & -0.41 & 5.67 \\
300 & 28.9 & 14.6 & 227 & -0.25 & 4.08 \\
315 & 28.7 & 1.9 & 0.61 & 0.00 & 0.91 \\
\hline
\end{tabular}

Frequency values measured by QCM during RH changes on the deposits showed complex changes at higher RH values. Origins of these results will be discussed briefly below. Some of the results show an expected trend and will be quantitatively analyzed. 
IR spectral changes with RH of the goethite only particle aggregates are shown in Figure 2 a) for wetting and Figure $2 \mathrm{~b}$ ) for drying. The $\mathrm{OH}$ stretching of water molecules is visible in all the IR spectra during the wetting/drying processes by a broad band from 3600 to $3000 \mathrm{~cm}^{-1}$ with a peak around $3410 \mathrm{~cm}^{-1}$ (Figure $2 \mathrm{a}$ ), b)). A sharp band around $3123 \mathrm{~cm}^{-1}$ is due to $\mathrm{OH}$ stretching of $\mathrm{Fe}-\mathrm{OH}$ species of goethite $[53,54]$. The $1640 \mathrm{~cm}^{-1}$ band is assigned to the bending vibration of $\mathrm{H}_{2} \mathrm{O}$ molecules [54]. The peaks around $890 \mathrm{~cm}^{-1}$ and $792 \mathrm{~cm}^{-1}$ are assigned to bending (deformation) vibrations of Fe$\mathrm{O}-\mathrm{H}$ of goethite [53].
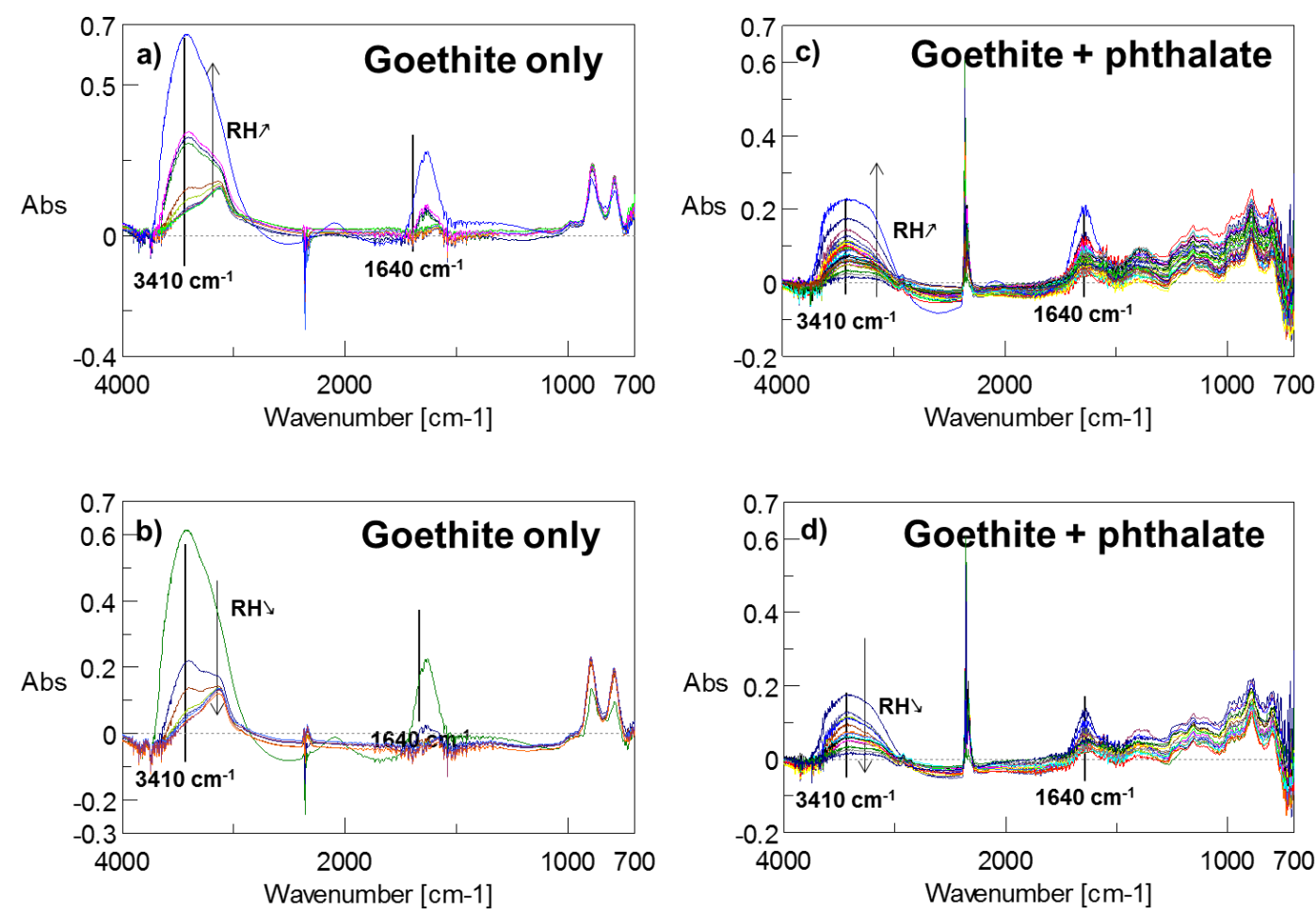

Figure 2: IR spectral changes with relative humidity (RH: \%) of the goethite only system during (a) wetting and (b) drying processes. c) and d) are for a phthalate sorbed goethite system during (c) wetting and (d) drying processes.

In Figure 3 a), the $\mathrm{OH}$ stretching band area of the goethite particle aggregates with a linear baseline from 3730 to $2995 \mathrm{~cm}^{-1}$ is plotted against RH. During the wetting process, a slight increase with RH is observed for low RH values, then a sharper increase above $60 \%$. A similar trend is found during the drying process. In Figure 4 a), the Fe-O-H band areas around $890 \mathrm{~cm}^{-1}\left(950-830 \mathrm{~cm}^{-1}\right)$ during the wetting and drying processes are plotted against $\mathrm{RH}$. The value is relatively constant at low RHs and decreases greatly at RH higher than $60 \%$. The Fe-O-H band area follows a similar trend for drying process, without hysteresis.

\section{IR spectral changes for goethite + phthalate system}

IR spectral changes with RH of the goethite + phthalate deposit are shown in Figure 2 c) for wetting and Figure $2 \mathrm{~d}$ ) for drying. The sharp band at $3123 \mathrm{~cm}^{-1}$ due to $\mathrm{OH}$ stretching of $\mathrm{Fe}-\mathrm{OH}$ species of goethite is not clearly observed in the goethite + phthalate system because of the strong overlap with a band around $3000 \mathrm{~cm}^{-1}$ probably coming from non-adsorbed or partially adsorbed phthalic acid molecules. The broad band in the $3600-3000 \mathrm{~cm}^{-1}$ region and the $1640 \mathrm{~cm}^{-1}$ band is overlapped with bands of phthalate/phthalic acid molecules. The peaks around $890 \mathrm{~cm}^{-1}$ and $792 \mathrm{~cm}^{-1}$ due to bending (deformation) of $\mathrm{Fe}-\mathrm{O}-\mathrm{H}$ of goethite are less visible than in the goethite only system. 
The $\mathrm{OH}$ stretching band areas were measured with a linear baseline from 3730 to $2995 \mathrm{~cm}^{-1}$ for the goethite + phthalate deposit during the wetting and drying processes and were plotted against $\mathrm{RH}$ in Figure $3 \mathrm{~b}$ ) (Table 2). This wavenumber region may include contributions from $\mathrm{OH}$ of goethite $(\mathrm{FeOOH})$ and phthalate $(\mathrm{COOH})$. The $\mathrm{OH}$ bands of goethite around $3125 \mathrm{~cm}^{-1}$ are principally kept unchanged, with some minor changes of surface $\mathrm{OH}$ species hydrogen-bonded to water molecules. Band area for the signal at around $1640 \mathrm{~cm}^{-1}$ has been monitored as well and showed a similar trend to the $\mathrm{OH}$ stretching band in Figure 3. The same position of the goethite particle aggregates on the goldcoated quartz crystal has been monitored throughout the entire experiment. As a consequence, any spectral change observed is attributed to water adsorption/desorption. As observed in the goethite only experiments, the $\mathrm{OH}$ stretching band of goethite + phthalate deposit first increased slightly with $\mathrm{RH}$ and greatly from $60 \%$ during the wetting process. The $\mathrm{OH}$ band follows the similar trend during the drying process but showing with a small hysteresis loop between $\mathrm{RH}=60-80 \%$ (Figure 3 b)). If compared to the goethite only system, the maximum band area is smaller.
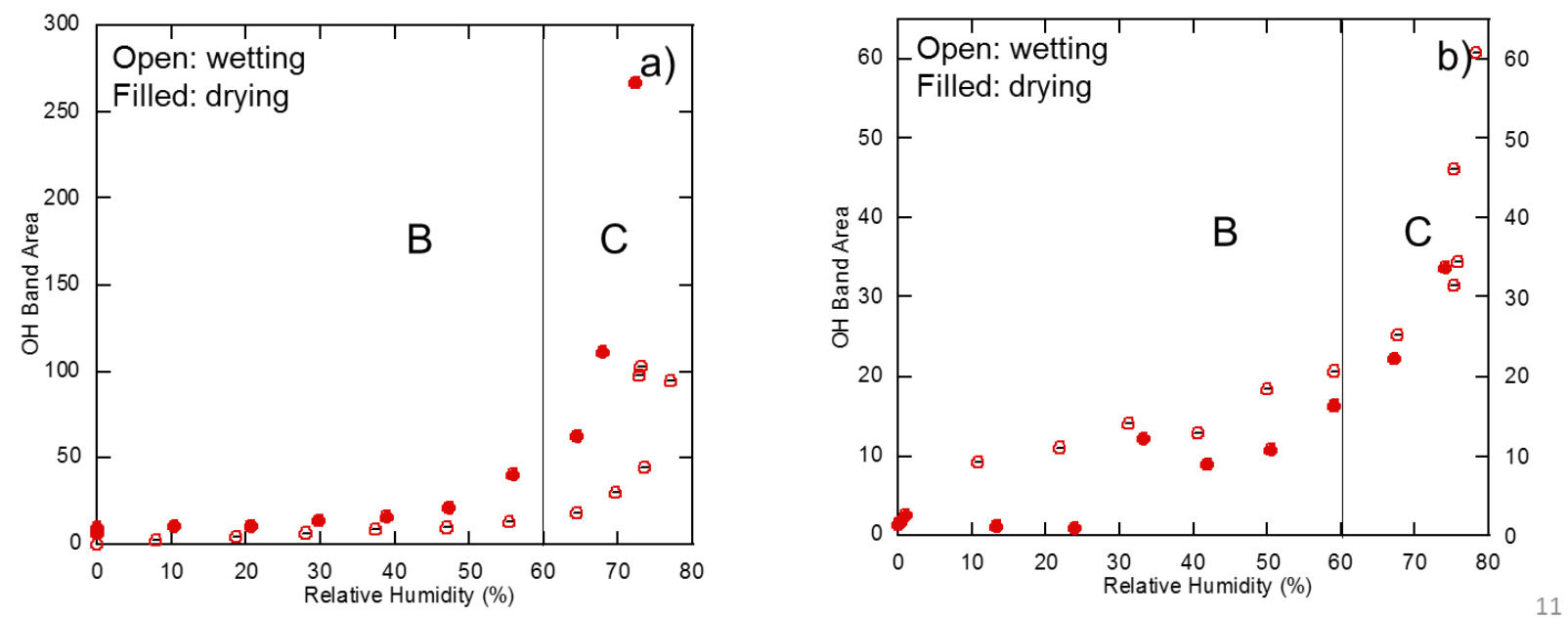

Figure 3: $\mathrm{OH}$ stretching band area as a function of relative humidity for a) goethite only and b) phthalate-adsorbed goethite. Open circles correspond to the wetting branch and closed circles to the drying branch. Vertical lines are guides to see the transitions between regions $\mathrm{B}$ and $\mathrm{C}$ mentioned in the literature [21], the region $\mathrm{A}$ is difficult to isolate.

Table 2. Time, temperature, relative humidity $(\mathrm{RH})$, frequency shift $(\Delta \mathrm{F})$, mass changes $(\Delta \mathrm{m})$ and total $\mathrm{OH}$ band area during wetting process of a goethite particle aggregates after adsorption of phthalates." " correspond to the points where the frequency shows complex behavior. 


\begin{tabular}{cccccc}
\hline $\begin{array}{c}\text { Time } \\
(\mathrm{min})\end{array}$ & $\begin{array}{c}\text { Temp } \\
\left({ }^{\circ} \mathrm{C}\right)\end{array}$ & $\begin{array}{c}\mathrm{RH} \\
(\%)\end{array}$ & $\begin{array}{c}\Delta \mathrm{F} \\
(\mathrm{Hz})\end{array}$ & $\begin{array}{c}\Delta \mathrm{m} \\
(\mu \mathrm{g})\end{array}$ & $\begin{array}{c}\text { Total OH } \\
\text { Band area }\end{array}$ \\
\hline 0 & 29.0 & 0 & 0 & 0 & 17.4 \\
15 & 29.0 & 6.6 & -21 & 0.02 & 21.32 \\
30 & 28.9 & 17.5 & -140 & 0.15 & 25.53 \\
45 & 28.8 & 27.3 & -132 & 0.14 & 27.66 \\
60 & 28.8 & 36.5 & - & - & 29.23 \\
75 & 28.8 & 45.9 & - & - & 31.53 \\
90 & 28.7 & 53.1 & - & - & 32.85 \\
105 & 28.6 & 60.1 & - & - & 36.65 \\
120 & 28.6 & 68.3 & -219 & 0.24 & 46.68 \\
135 & 28.7 & 75.6 & 1253 & -1.36 & 57.26 \\
150 & 28.6 & 75.6 & -46 & 0.05 & 48.28 \\
165 & 28.6 & 75.3 & -1257 & 1.36 & 51.24 \\
180 & 28.6 & 78.1 & -3677 & 3.98 & 81.93 \\
195 & 28.6 & 73.9 & 3802 & -4.12 & 40.62 \\
210 & 28.5 & 66.7 & - & - & 34.00 \\
225 & 28.5 & 58.9 & - & - & 28.97 \\
240 & 28.5 & 50.5 & - & - & 25.67 \\
255 & 28.4 & 42.1 & - & - & 26.55 \\
270 & 28.5 & 33.2 & -194 & 0.21 & 21.76 \\
285 & 28.4 & 24.7 & 298 & -0.32 & 14.91 \\
300 & 28.4 & 13.9 & 284 & -0.31 & 15.81 \\
312 & 28.4 & 2.3 & 214 & -0.23 & 14.62 \\
\hline
\end{tabular}

The Fe-O-H band areas around $890 \mathrm{~cm}^{-1}\left(950-830 \mathrm{~cm}^{-1}\right)$ of the goethite + phthalate deposit during the wetting and drying processes were plotted against RH (Figure $4 \mathrm{~b}$ )). During wetting, it increases quasi-linearly at low RHs $(<30 \%)$, remains relatively constant at $\mathrm{RH}=30-60 \%$ and decreases at RH higher than $60 \%$. The band area does not show a similar trend for drying process: first the band increases greatly, then a decrease is observed around $30 \%$ relative humidity.
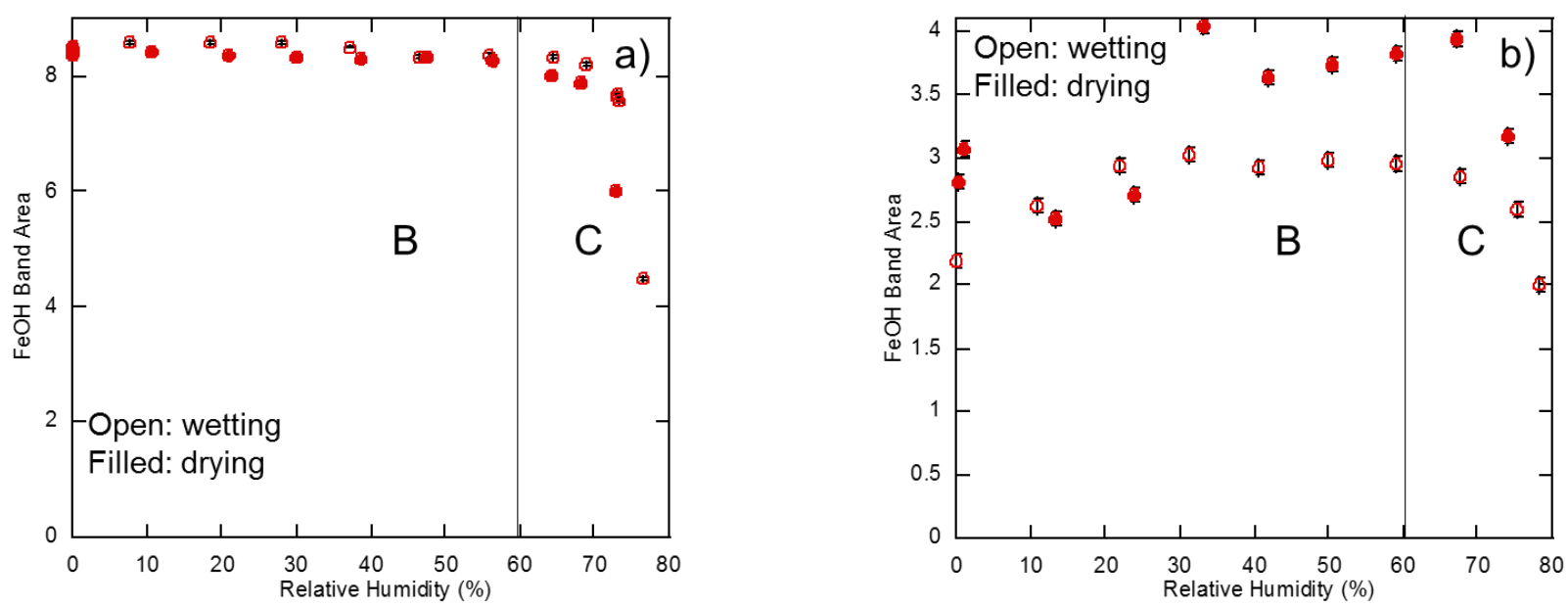

Figure 4: Fe-O-H bending band areas as a function of relative humidity for a) goethite only and b) phthalate adsorbed goethite. Open circles correspond to the wetting branch and closed circles to the drying branch. Vertical lines are guides to see the transitions between regions $\mathrm{B}$ and $\mathrm{C}$ mentioned in the literature [21]. 


\section{Discussion}

\section{Amounts of water adsorbed to the goethite particle aggregates with and without phthalate}

Quartz Crystal Microbalance (QCM) data on frequency changes of the QCM sensor during wetting/drying cycles of goethite (+phthalate) deposits gave complex changes with RH at higher RHs (figures not shown). At low RHs $(\mathrm{RH}<50 \%)$, QCM frequencies decreased with RH with some fluctuations. Between RHs of 50 to $75 \%$, frequencies showed complex fluctuations with RH. These changes can be related to viscoelastic perturbations due to adsorption of multiple water molecular layers and structural modification of aggregates of goethite nanoparticles. As RH is raising, small menisci may appear between the grains of goethite (and especially at contact points between the grains at first), applying some hydrostatic pressure on the solid particles. As a result, the forces applied may be responsible for small displacements of the grains with respect to their resting (dry) state. Moreover, the formation of menisci is associated with the appearance of a liquid phase between the grains. It is possible that electric charge is building up on the surface that is producing some small rearrangements of the deposit, impairing the oscillations of the QCM device [54]. The deposit is contacting the gold surface of the QCM plate and the small displacements of the grains may change the oscillating frequency of the plate and eventually change the resulting current, producing some important changes in the measurements. At RH of about $75 \%$ to $78 \%$, QCM frequencies decreased greatly, in agreement with the significant increase of $\mathrm{OH}$ band areas (Figure 3).

The final values of $\Delta \mathrm{F}(\mathrm{Hz})$ during each $\mathrm{RH}$ step for $\mathrm{RH}=0-50 \%$ and $78 \%$ can be converted to mass changes $\Delta \mathrm{m}(\mu \mathrm{g})$ (Table 2). In Figures 5 and 6 , they have been plotted against the total $\mathrm{OH}$ band areas (shown in Figure 3). For the goethite only system, $\mathrm{OH}$ band area shows a quasilinear trend with the cumulated mass change area from 0 to around $1.5 \mu \mathrm{g}$ (Figure $5 \mathrm{a}$ )), while the goethite + phthalate system shows a different trend with the cumulated mass change (Figure 6 a)), resulting in a strong hysteresis phenomenon. Such measurements reflect the evolution of the integrated molar absorption coefficient with the change of surface hydration state. The differences between Figure 5 and Figure 6 shine a light on the difference of interaction of water vapor with goethite surface after adsorption of phthalate. However, such changes should be interpreted with caution as they correspond to an average of the many $\mathrm{OH}$ species present in the system. The water mass measurements by QCM are not converted to numbers of water layers, because high levels of approximation are necessary. We prefer to stay on a monolayer/multilayer picture of the surface hydration.

For more quantitative comparison, the $\mathrm{OH}$ band areas should be normalized by some band areas characteristic of the solid. Although the Fe-O-H band area showed unexpected changes for the goethite + phthalate system (Figure $4 \mathrm{~b}$ )), it is the most representative band of goethite. Therefore, the normalized $\mathrm{OH}$ band areas were divided by the $\mathrm{Fe}-\mathrm{O}-\mathrm{H}$ band areas and are plotted against $\mathrm{RH}$ in Figure 7. The use of the normalization enables to confirm the changes of the $\mathrm{OH}$ band area with respect to the amount of solid. The presence of phthalate molecules adsorbed on the goethite surface results in a hysteresis loop on the $\mathrm{OH}$ band area. 

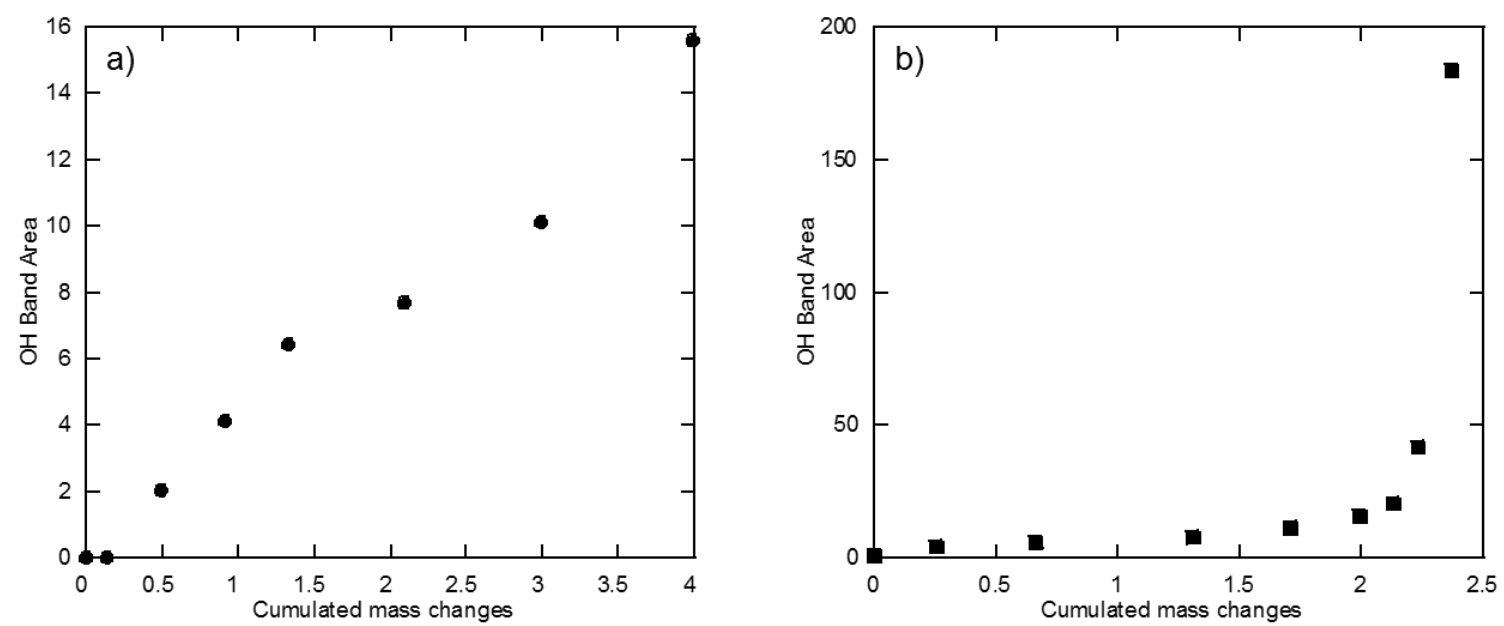

Figure 5: $\mathrm{OH}$ stretching band areas as a function of cumulated mass changes of a goethite film for the a) wetting branch and b) drying branch.
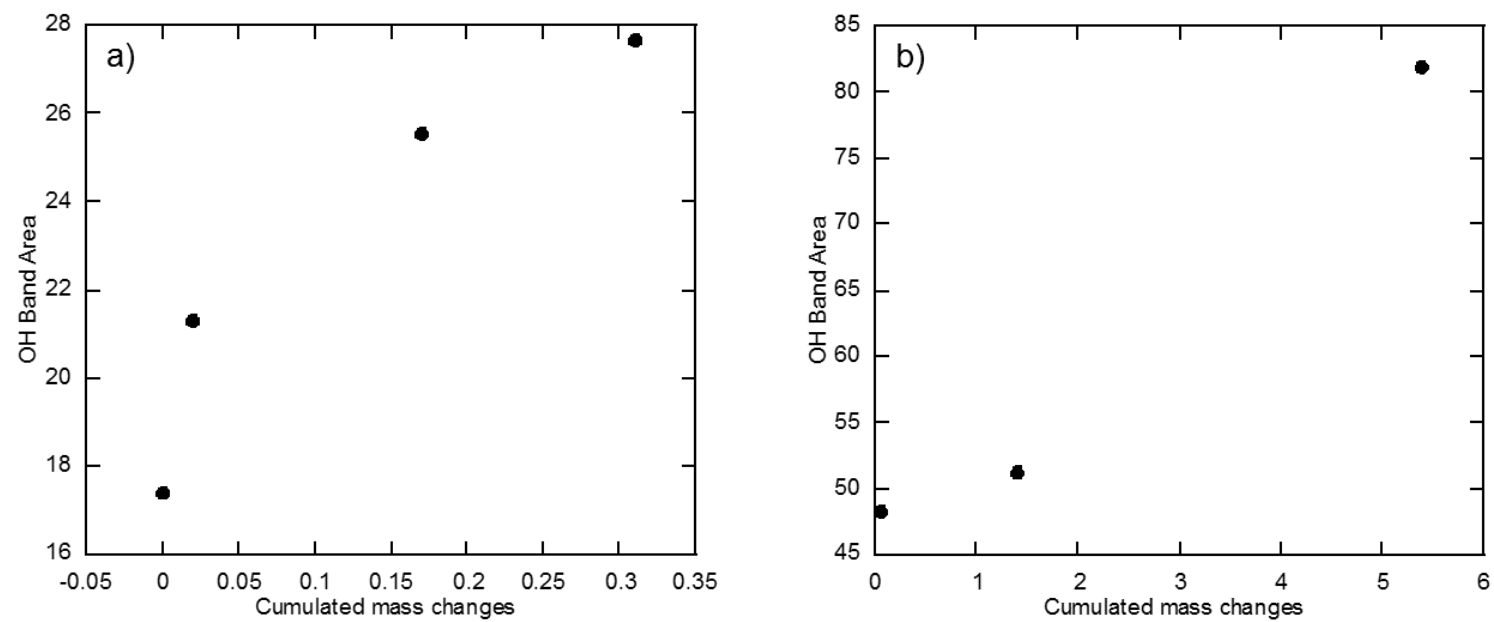

Figure 6: $\mathrm{OH}$ stretching band areas as a function of cumulated mass changes of a phthalate adsorbed goethite particle aggregates for the a) wetting branch and b) drying branch.

Weight ratios of adsorbed water to goethite particle aggregates are about 3.6 times larger for the goethite only system than the goethite + phthalate system at about $\mathrm{RH}=78 \%$ (Tables 1 and 2). On the other hand, the normalized $\mathrm{OH}$ band area are about 1.6 larger for the goethite only system than the goethite + phthalate system at about $\mathrm{RH}=78 \%$ (Figure 7). It should be noted that this factor can be considered as a minimum value, since the surface Fe-O-H bands can be decreased by the adsorbed phthalates on the goethite surface. Thus, the presence of phthalate on the goethite particle aggregates was found to decrease greatly the adsorption behavior of water both from the QCM data and the infrared $\mathrm{OH}$ bands. 

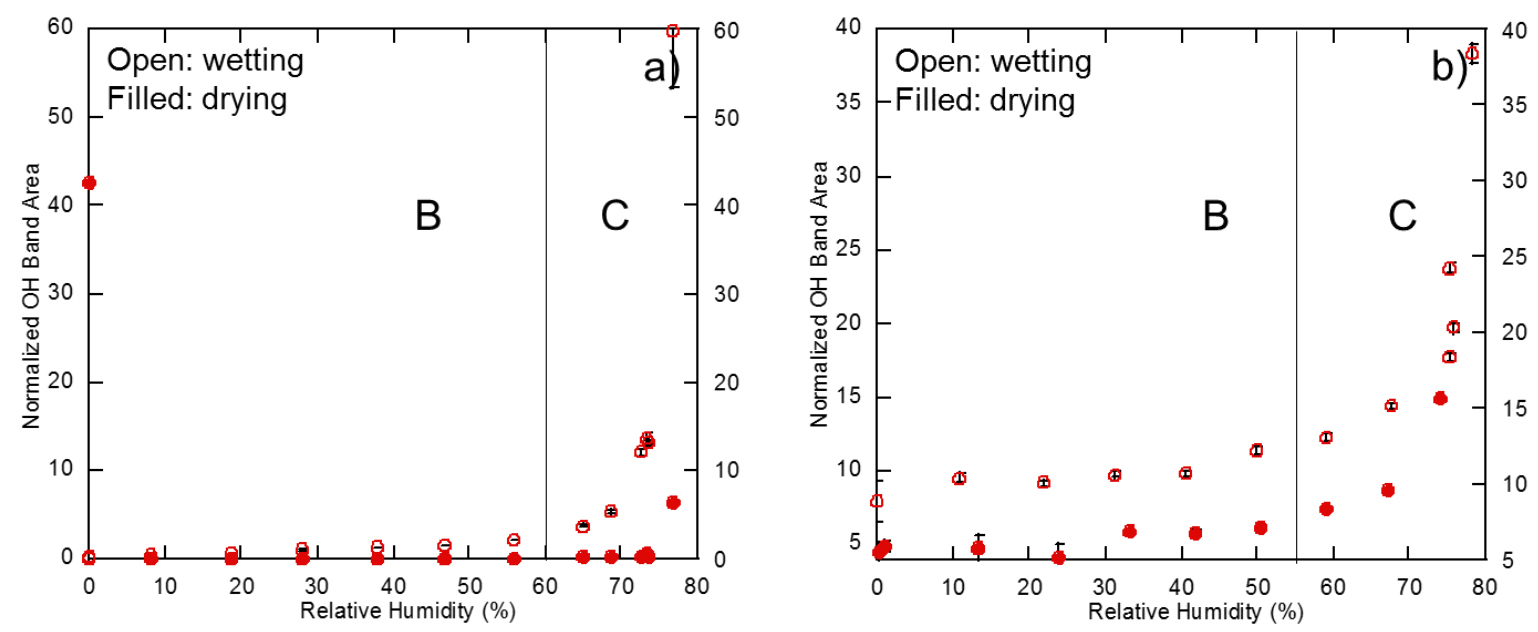

Figure 7: Normalized $\mathrm{OH}$ stretching band areas (divided by Fe-O-H band areas) as a function of relative humidity for a) goethite only and b) phthalate adsorbed goethite. Open circles correspond to the wetting branch and closed circles to the drying branch. Vertical lines are guides to see the transitions between regions B and C mentioned in the literature [21].

\section{Water adsorption isotherms}

Before examining phthalate bands, we will first discuss shapes of the water adsorption isotherms of the goethite only and goethite + phthalate systems. Since adsorbed water masses could not be obtained for all the $\mathrm{RH}$ range, the normalized $\mathrm{OH}$ band areas will be used for representing adsorption isotherms (Figure 7). These can be discussed in terms of three regions based on some typical literatures for adsorption isotherms [57, 21]: region A; monolayer adsorption of ice-like water molecules, region $\mathrm{B}$; multilayer adsorption of various water molecules, region $\mathrm{C}$; capillary condensation of liquid-like water. Ice-like water corresponds to water molecules strongly interacting with the surface via short hydrogen bonding. This strong interaction is very likely to impair the mobility of these water molecules at the surface and therefore limit any transport in this relative humidity region. On the other hand, $\mathrm{C}$ region is mainly composed of liquid-like water molecules whose properties (such as mobility) are close to those of liquid water. Transport phenomena are assumed to be favored in this region. $\mathrm{B}$ region is a transition region and exhibit a mixture of the respective behaviors of $\mathrm{A}$ and $\mathrm{C}$.

For the goethite only system, the adsorption isotherm appears to have S shape with region A possibly between $\mathrm{RH}=0-30 \%$ based on a literature [21] with only minor amounts of adsorbed water. Based on the surface of deposited goethite and the adsorbed water mass, the thickness of the water can be estimated to $0.84 \mathrm{~nm}$ for $8.1 \% \mathrm{RH}$. For the region $\mathrm{B}$, the water mass is unknown, and this calculation cannot be made. For the region $\mathrm{C}$, the thicknesses of water layers can be more than $6.5 \mathrm{~nm}$ (ca $67.8 \%$ RH, see Table 1), which is consistent with the thickness threshold for the liquid-like expected behavior. For the goethite + phthalate system, the adsorption isotherm has also a $\mathrm{S}$ shape with region $\mathrm{B}$ for $\mathrm{RH}=30-55 \%$ and region $\mathrm{C}$ above $55 \%$, rather similar to the goethite only system. Region A is difficult to isolate. Due to the fact that the sample is composed of particle aggregates instead of a flat surface as studied in the literature [21], it has been difficult to interpret the data in terms of numbers of water layers (one, two...). For this reason, only the region A (mono to few-layers) and region $C$ (multilayers) are considered. It could result from the low surface area $\left(S_{\mathrm{BET}}=29.2 \mathrm{~m}^{2} \cdot \mathrm{g}^{-}\right.$ ${ }^{1}$ ) of the goethite used and therefore the expected increase of the band area of the A region is difficult to be observed.

\section{Phthalate Bands (COOH)}

A magnification of the IR spectra focused on phthalate/phthalic acid molecules are shown in the supporting information part (Figures S1 and S2). An IR band in the $3000-2830 \mathrm{~cm}^{-1}$ region 
results from the combinations of fundamental bands of $\mathrm{COOH}$ groups of fully or partially protonated phthalic acid [59]. Due to its smaller bandwidth with respect to the other wide signals $\left(3730-2995 \mathrm{~cm}^{-}\right.$ ${ }^{1}$ ), this band is always observed throughout the hydration/dehydration cycle. Moreover, they are isolated, which is not the case in the $1770-1300 \mathrm{~cm}^{-1}$ wavenumber range, characteristic of the carboxylic acid/carboxylate signals. The band area is plotted vs. time in Figure 8a. The COOH combination band area increases gradually from $\mathrm{RH}=0$ to $76 \%$ but drops around the highest $\mathrm{RH}=$ $78 \%$. Upon the start of dehydration step, the $3000-2830 \mathrm{~cm}^{-1}$ band increases and returns to its value at ca $76 \mathrm{RH} \%$. A partially reversed trend with some fluctuations is observed during the drying process. Results can be displayed in the form of an isotherm in Figure 8 b), where the same trend as Figure 8 a) as a function of RH can be observed.
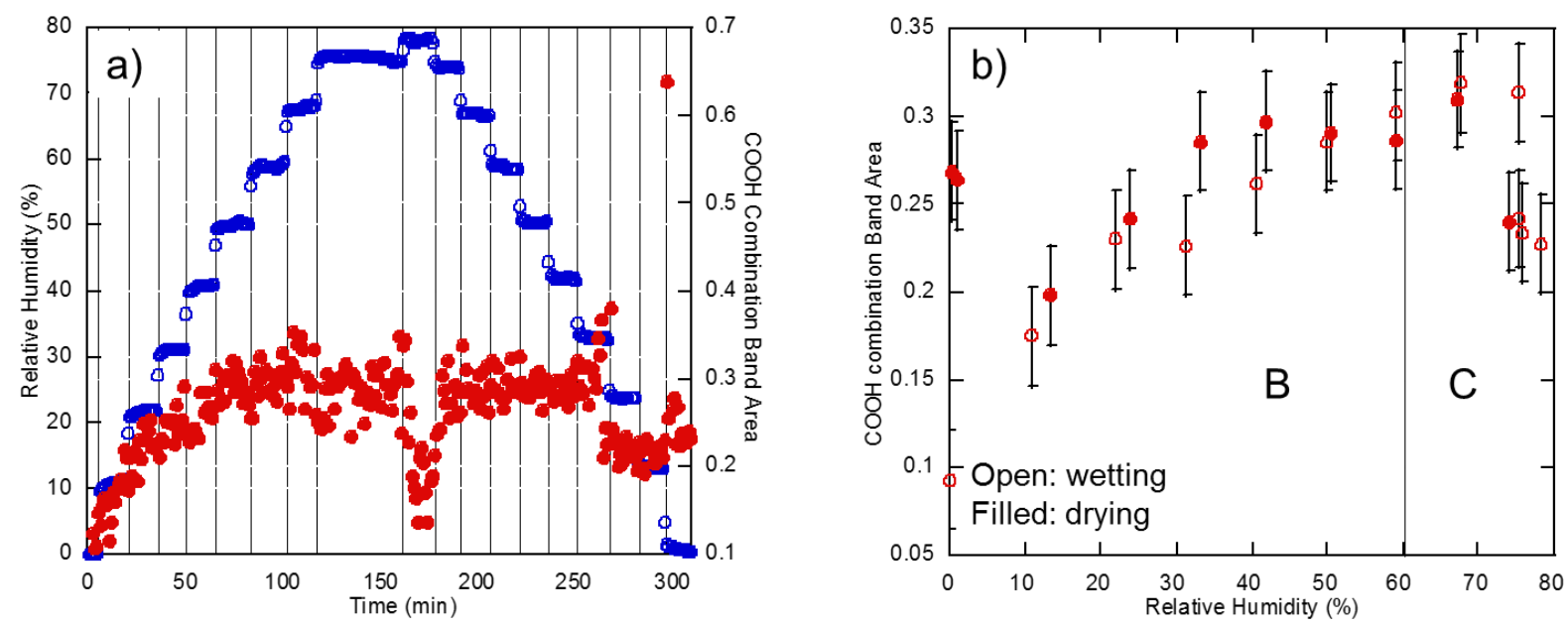

Figure 8: a) Evolution of the $\mathrm{COOH}$ combination band area (red filled circles) and relative humidity (blue open circles) as a function of time. Vertical lines are separating the increases and decreases of RH. b) Evolution of the $\mathrm{COOH}$ combination band area as a function of relative humidity. Open circles correspond to the wetting branch and filled circles to the drying branch. The vertical line is a guide to see the transition between regions $\mathrm{B}$ and $\mathrm{C}$.

It should be noted that the $\mathrm{COOH}$ band does not follow the $\mathrm{RH}$ change steps but shows somewhat a gradual change. This is very surprising, since even if the change is related to kinetics of the evolution of the $\mathrm{COOH}$ group, it should at least be influenced by the increase of the thickness of the water film on the solid surface. A possible explanation would be the relation between the increase of $\mathrm{COOH}$ band and the protonation of $\mathrm{COO}^{-}$groups of phthalate adsorbed on the positively charged goethite surface. Indeed, the molecular water adsorbed at the goethite surface might dissociate to provide protons to form carboxylic acid. The resulting $\mathrm{OH}^{-}$would react with the protonated surface groups of goethite to give $\mathrm{Fe}-\mathrm{O}-\mathrm{H}$ species. In fact, the $\mathrm{Fe}-\mathrm{O}-\mathrm{H}$ band area shows similar kinetic behavior to the $\mathrm{COOH}$ bands, supporting such a mechanism (Figure 9). 

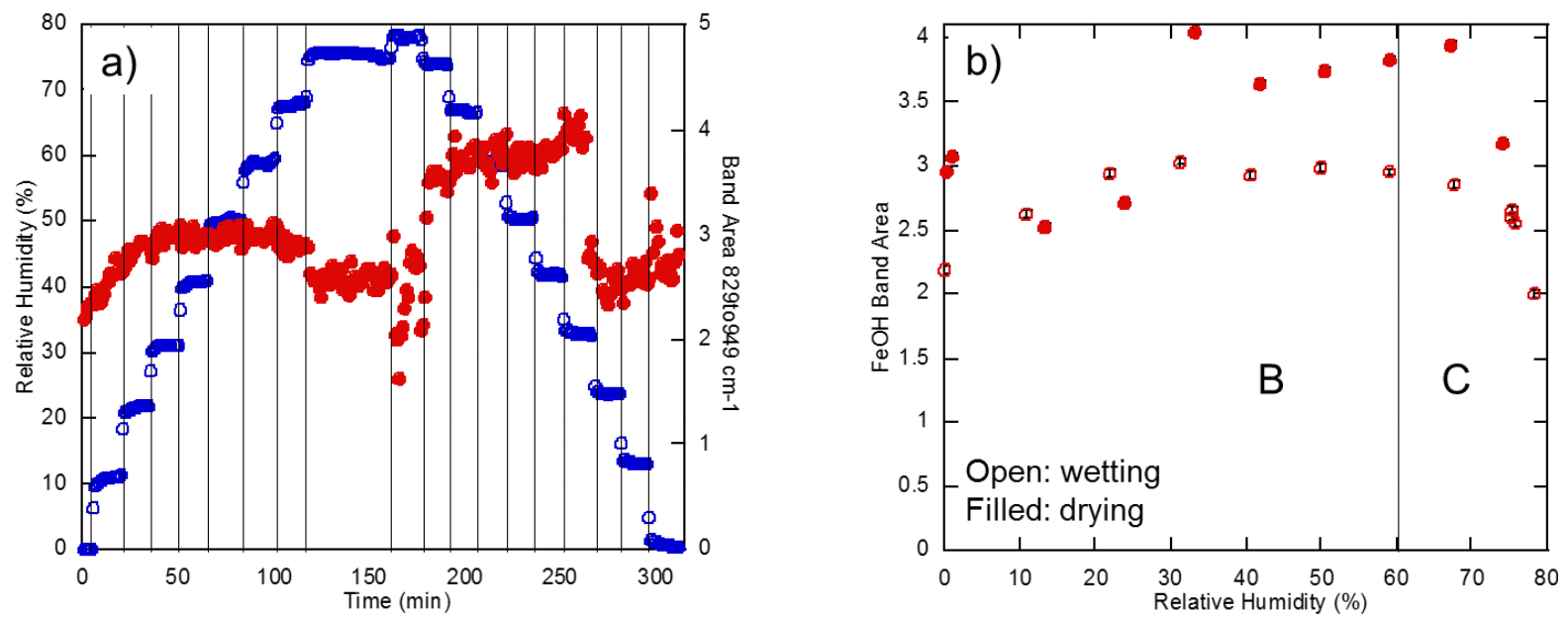

Figure 9: a) Evolution of the $\mathrm{FeOH}$ bending band area (red filled circles) and relative humidity (blue open circles) as a function of time. Vertical lines are separating the increases and decreases of RH. b) Evolution of the FeOH bending band area as a function of relative humidity. Open circles correspond to the wetting branch and filled circles to the drying branch. The vertical line is a guide to see the transition between regions B and C based on the literature [21].

The sudden decrease of the $\mathrm{COOH}$ band at $\mathrm{RH}>76 \%$ corresponds to the region $\mathrm{C}$ with the presence of liquid-like water. In these conditions, the system is closer to the solid/solution equilibrium, dominated by the adsorption of carboxylate ions. Therefore, this decrease can be explained by the deprotonation of $\mathrm{RCOOH}$, which results in a lower concentration of carboxylic groups.

\section{Phthalate Bands (CO)}

IR bands in the $1130-1191 \mathrm{~cm}^{-1}$ region are considered to be due to stretching of CO groups of phthalate [59]. The $\mathrm{CO}$ band areas are plotted against time together with RH values (Figure $10 \mathrm{a}$ )). The $\mathrm{CO}$ band area increase gradually with time from $\mathrm{RH}=0$ to $76 \%$ but decreased greatly around the highest $\mathrm{RH}=78 \%$. As observed in the analysis of the $\mathrm{COOH}$ phthalate bands, a complete reversibility of the decrease of the $\mathrm{CO}$ band upon the start of the dehydration procedure is observed. For the rest of the dehydration process, band area showed a reverse trend with some fluctuations during the drying process (Figure $10 \mathrm{a}$ )).

The trend of this $\mathrm{CO}$ band is very similar to the one of the $\mathrm{COOH}$ band (Figure $8 \mathrm{a}$ )). This increase of $\mathrm{CO}$ stretching band confirms the protonation of $\mathrm{COO}^{-}$groups of phthalate adsorbed at the goethite surface. The inverse changes of the $\mathrm{CO}$ band area together with that of the $\mathrm{COOH}$ band around $\mathrm{RH}=78 \%$ (Figure 8 a), Figure $10 \mathrm{a}$ )) can be interpreted as the deprotonation of the phthalic acid in contact with bulk water at $\mathrm{pH}$ higher than its $\mathrm{pK}_{\mathrm{a}}$.
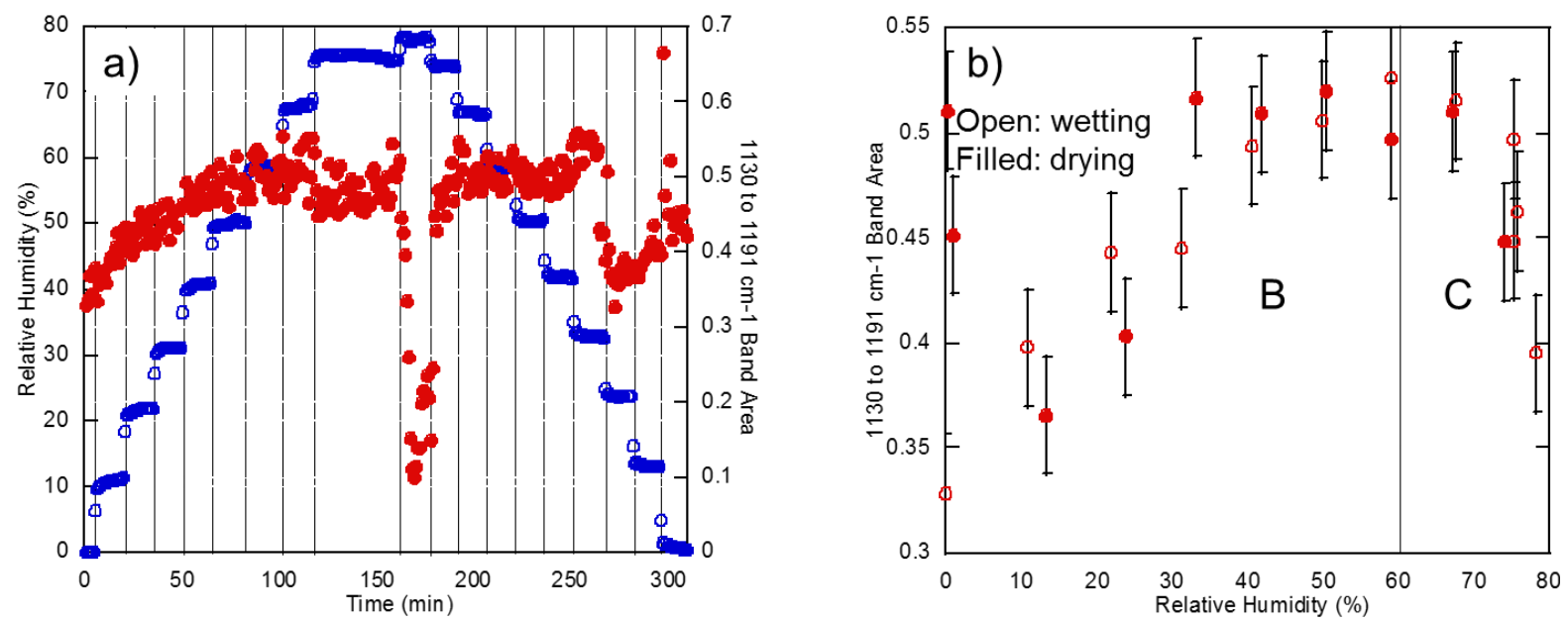

Figure 10: a) Evolution of the CO stretching band area (red filled circles) and relative humidity (blue open circles) as a function of time. Vertical lines are separating the increases and decreases of RH. b) Evolution of the CO stretching band area as a function of relative humidity. Open circles correspond to the wetting branch and filled circles to the drying branch. The vertical line is a guide to see the transition bet $\$$ Aen regions B and C based on the literature [21], but region $\mathrm{A}$ is difficult to isolate. 


\section{Phthalate adsorption model}

Based on the above results and discussion, the following model for phthalate behavior during its adsorption on goethite can be proposed.

The phthalate species are considered to be adsorbed on the goethite surface during the 24 hours stirring of the mixture with a surface coverage of $0.8 \mu \mathrm{mol} . \mathrm{m}^{-2}$, mainly in the form of inner sphere complex both in the monodentate and the bidentate forms [59]. After dehydration of the suspension on the QCM plate, surface density of phthalate is expected to be $1.6 \mu \mathrm{mol} . \mathrm{m}^{-2}$. Under optical microscope, $\mathrm{NaCl}$ crystals have been observed in the dried phthalate-goethite particle aggregates on the QCM sensor. Although no elemental analysis has been performed on the crystals, the fact that the same images are observed during the experiment on goethite alone tends to confirm their chemical identity. Moreover, $\mathrm{NaCl}$ was a thousand time more concentrated than phthalic acid in the suspension, thus $\mathrm{NaCl}$ reaches its solubility limit long before sodium phthalate does. While $\mathrm{NaCl}$ crystallization is starting, the concentration of $\mathrm{Na}^{+}$and $\mathrm{Cl}^{-}$is above the solubility limit (ca $6 \mathrm{M}$ ) and is impairing both outer-sphere and inner sphere complex formation [56]. Therefore, the subsequent water evaporation leads to the precipitation of $\mathrm{NaCl}$, and sodium phthalate remains under-saturated, allowing the adsorption of phthalate species. Even though sodium phthalate is not expected to precipitate, byproducts of the drying phenomenon could be solvated ion pairs with $\mathrm{Na}^{+}$ions or the surface (i.e. outer sphere complexes).

One way to understand these experimental observations is the following model: with increasing RH, water is going to substitute part of the phthalate molecules adsorbed on the goethite surface, forming partially desorbed and therefore unstable carboxylate moiety such as the following reaction scheme:

$$
\phi_{\mathrm{COO}}^{\mathrm{COO}} \mathrm{Fe}+\mathrm{H}_{2} \mathrm{O} \rightarrow \phi_{\mathrm{COO}^{-}}^{\mathrm{COO}} \mathrm{Fe}-\mathrm{H}_{2} \mathrm{O}
$$

$\phi_{\mathrm{COO}^{-}}^{\mathrm{COO}}$ designates the phthalate molecule with adsorbed $(\mathrm{COO})$ moiety and free $\left(\mathrm{COO}^{-}\right)$moiety. From this reaction scheme, the initial state is assumed to be a physically sorbed bidentate surface complex, which is implied by the existence of the reversibility of the $\mathrm{C}$ region (ca 78\% RH). The chemical sorption of phthalate molecules can occur either as a monodentate or a bidentate configuration. The hydration of the surface can induce a protonation and desorption of a carboxylate group of the adsorbate. If the monodentate surface complex is protonated, it becomes an outer-sphere complex free to diffuse outside of the IR spot at high relative humidity. As a complete reversibility of the $\mathrm{COOH}$ and $\mathrm{CO}$ band areas is observed between hydration and dehydration cycles, such expected transport did not take place. This can be explained by the fact that the phthalate molecule are still anchored to the surface by another $\mathrm{COO}$. Thus, this surface reaction is leaving one $\mathrm{COO}^{-}$still bound to goethite surface. This type of behavior has been noticed in another work studying the behavior of formic acid in water unsaturated atmosphere [10]. Although water can solvate carboxylate groups in aqueous solution, the thin water film is preventing to have solvation shell stabilizing the $\mathrm{COO}^{-}$group newly formed, and a chemisorbed surface water could deprotonate and trigger a proton transfer to form a carboxylic acid group that is able to fit in the hydrogen bond network of the surface. This would result in the formation of new hydroxyl groups parallel to the protonation of carboxylic acid.

$$
\phi_{\mathrm{COO}-}^{\mathrm{COO}} \mathrm{Fe}-\mathrm{H}_{2} \mathrm{O} \rightarrow \phi_{\mathrm{COOH}}^{\mathrm{COO}} \mathrm{Fe}-\mathrm{OH}
$$

By the formation of a carboxylic group, a band at $1700 \mathrm{~cm}^{-1}(\mathrm{C}=\mathrm{O}$ stretching $)$ would be expected to appear, but could not be recognized in the spectra. Interaction of the $\mathrm{COOH}$ with surfacebonded ice-like water could red-shift this $\mathrm{C}=\mathrm{O}$ band overlapping with $\mathrm{COO}^{-}$and $\mathrm{H}-\mathrm{O}-\mathrm{H}$ bands around $1600 \mathrm{~cm}^{-1}$. Strong hydrogen bonding, such as in carboxylic acids for example, has been known to shift IR bands of carboxylic acids tremendously (around $100 \mathrm{~cm}^{-1}$ ) [60]. Strong hydrogen bonding is also 
found at the surface of metal oxide at low relative humidity, thanks to the ice-like water molecules and would explain why typical signals of $\mathrm{COOH}$ moieties are not observed in the spectra. Such a trend is confirmed by the DFT calculations.

At highest RHs with capillary condensation of liquid-like water, the acid-base equilibrium of carboxylate group at $\mathrm{pH}>\mathrm{pKa}$ could take place to deprotonate $\mathrm{COOH}$ forming hydronium ion $\mathrm{H}_{3} \mathrm{O}^{+}$:

$$
\phi_{\mathrm{COOH}}^{\mathrm{COO}} \mathrm{Fe}-\mathrm{OH}+\mathrm{H}_{2} \mathrm{O} \rightarrow \phi_{\mathrm{COO}-}^{\mathrm{COO}} \mathrm{Fe}-\mathrm{OH}+\mathrm{H}_{3} \mathrm{O}^{+}
$$

Since the partially deprotonated phthalates are still confined to the surface, they will be returned back to dimer upon drying of liquid-like water.

In order to confirm the above interpretation, DFT calculations have been performed. The calculations are detailed in the materials and methods section. After finding the most stable phthalate molecule on the (001) facet, which is a binuclear adsorption mode, more stable by $0.6 \mathrm{eV}$ than the mononuclear one, we gradually completed the coordination sphere of the surface Fe atoms. In total, 25 configurations were studied, where the positions of the water molecules were changed in order to reach the best local minimum. More adsorbed water molecules warrant more configurations tested per model. Again, the scope of the study was not to perform an exhaustive study of the potential energy surface, but rather to compare, at a given water coverage, and in a given water configuration, the mono- versus binuclear configurations of phthalate adsorption. The binuclear configuration is compared to the configuration with the same amount of water molecules adsorbed, but in which the phthalate adsorption mode is mononuclear. The schematic view in Figure 11 aims at helping to understand how the phthalate molecule is interacting with the surface, as well as the fate of the vicinal $\mathrm{Fe}$ sites. the site "Fe 1" is the site accepting the COO moiety in a bidentate adsorption mode. The sites "Fe 3" and "Fe 4" are saturated with two adsorbed water molecules. The site "Fe 2" receives either the $\mathrm{COOH}$ adduct, the $\mathrm{COOH}$ adduct and one water molecule, or two water molecules. When phthalate is adsorbed only on "Fe 1", the adsorption is mononuclear. When phthalate is co-adsorbed on "Fe 1" and " $\mathrm{Fe} 2$ ", the adsorption is binuclear.

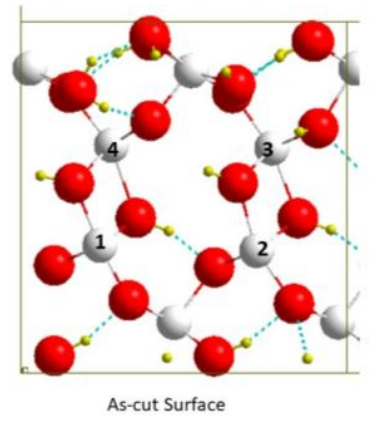

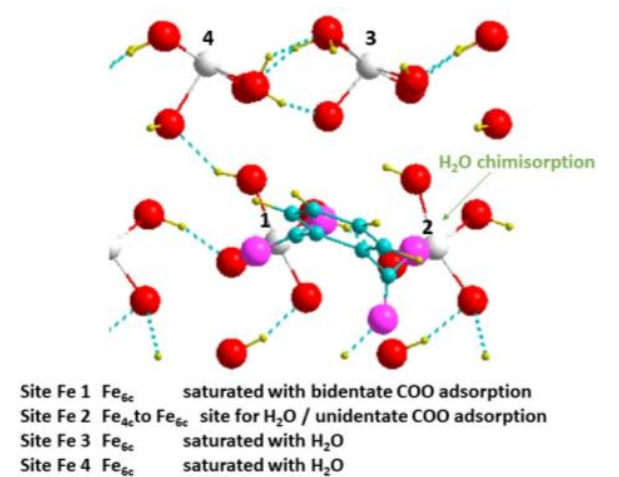

Figure 11: Schematic views from above :a) pristine (001) surface a) and $b$ ) with phthalate adsorbed on the goethite surface (001) surfaces.

For example, the bidentate (Bi) configuration $(\mathrm{Bi}, 1,0)$, in which "Fe 2" coordination is saturated, is compared to the monodentate (Mono) configuration with the same water loading, (Mono, $1,0)$ in which "Fe 2" is 5 fold coordinated. Note that in the mononuclear configuration, a surface proton is transferred to the desorbed $\mathrm{COO}$ to stabilize the $\mathrm{COOH}$ moiety. This re-protonation of $\mathrm{COO}$ was indeed observed experimentally in the present work (see above).

The most stable configurations obtained are reported in Table 3. For each water coverage, both configurations, mononuclear and binuclear are reported, together with the difference in energy between these configurations. It clearly appears that, at low water loading ( 4 water molecules adsorbed on iron atoms, coverage 4.2 molecule $/ \mathrm{nm}^{2}$ ), the binuclear configuration is more stable by $0.61 \mathrm{eV}$ than the mononuclear one, which is explained by the fact that the surface iron "Fe 2" has not its full coordination sphere. This is also true for the water loading 5.3 molecules. $\mathrm{nm}^{-2}$, for which the "Fe 2 " is penta-coordinated (5c), thus its coordination sphere is not complete. Adding one water molecule 
(coverage 6.4 molecules.nm ${ }^{-2}$ ), now the coordination sphere of all Fe are complete, and the difference in the structures is that in the binuclear mode, the substituted water molecule is physisorbed at the surface. Now, the configurations are iso-energetic. This can be understood in the following way: the difference between mono- and bidentate being around $0.6 \mathrm{eV}$ when no additional physically adsorbed water is present, the loss of energy due to the bidentate to monodentate transition may be compensated by the energy of one water molecule physisorbed at the surface.

From water loading 7.4 molecules.nm ${ }^{-2}$ and above, the additional water molecules are physically sorbed at the surface. Now, the mononuclear configuration is more stable than the binuclear one. We note that additional water molecules tend to form a solvation-like structure around the $\mathrm{COOH}$ moiety. In the calculations, no spontaneous $\mathrm{COOH}$ deprotonation was observed. However, direct correspondence of this simple DFT modeling with a minimal number of water molecules to the multi-layer adsorption models of water on the goethite surface including the formation of "liquid-like water film" is difficult. The possibility of local solvation of $\mathrm{COOH}$ to $\mathrm{COO}^{-}$by co-adsorbed water molecules will be studied in a next paper.

Table 3: Most stable configurations obtained as a function of water loading for $0,1,2,3,4$ and 5 water molecules (values of molecule $/ \mathrm{nm}^{2}$ are shown). The energy differences between bidentate $(\mathrm{Bi})$ and monodentate (Mono) configurations $(\Delta \mathrm{E}=\mathrm{Mono}-\mathrm{Bi})$ are given in $\mathrm{eV}$.

554

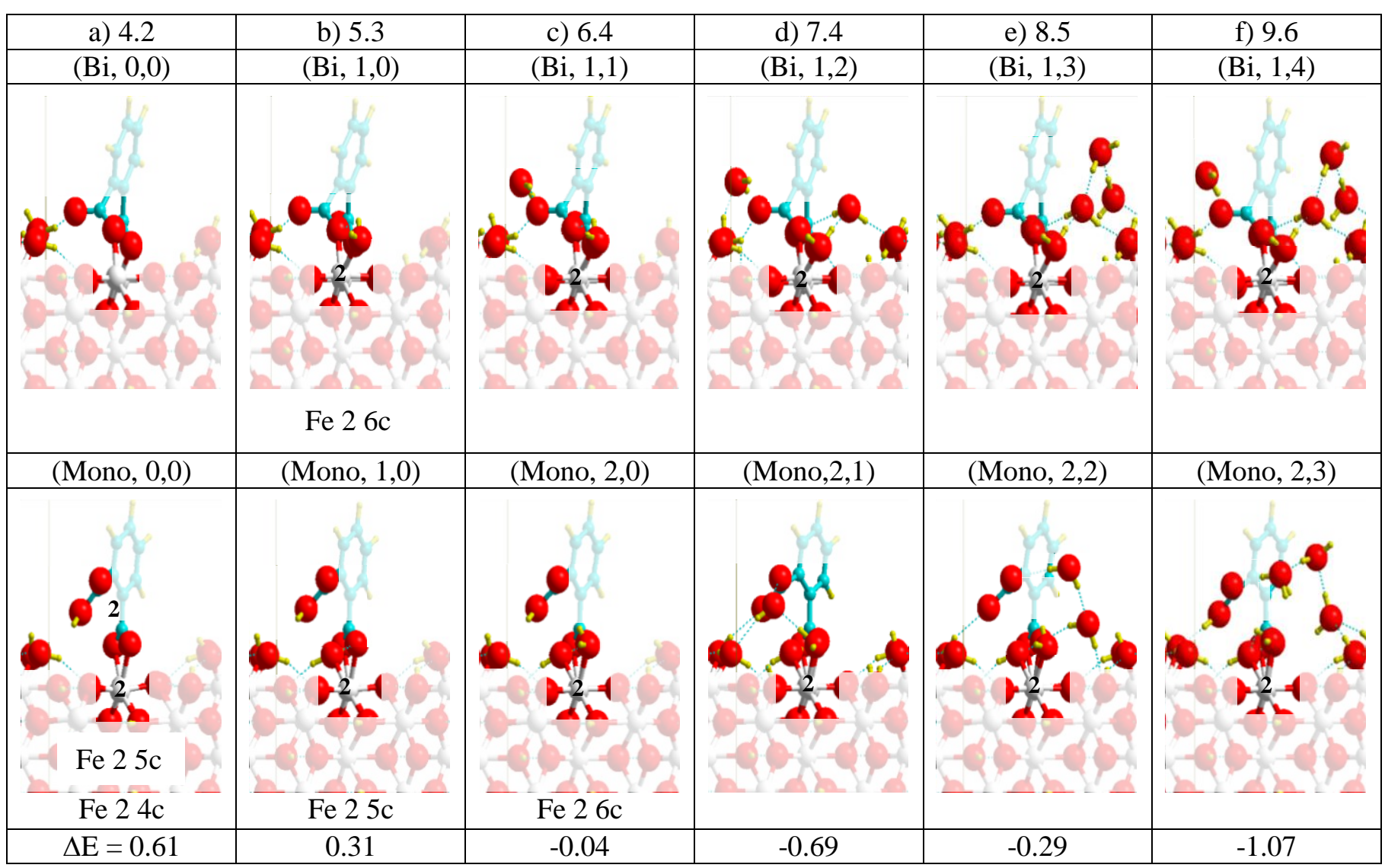

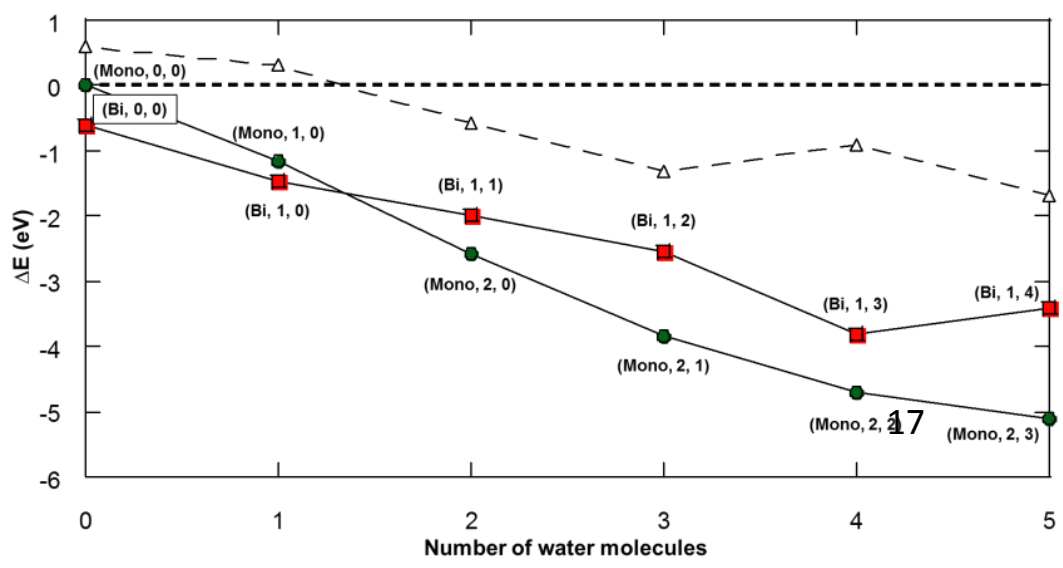

Figure 12: Adsorption energies of water on $\alpha-\mathrm{FeOOH}$ (001) (with phthalate pre-adsorbed, as a function of the number of water molecules adsorbed for the monodentate (Mono: green circles) and the bidentate (Bi: red squares) adsorption modes. The dashed line represents the net difference between the energies of the two structures (values shown in Table 3). 
Figure 12 shows the cumulative adsorption energies of water at the goethite surface, in the case of monodentate and bidentate adsorption. Both curves have a negative slope, indicating the stabilization of the system with water loading. The water adsorption energy for monodentate adsorption is higher than that for the bidentate adsorption at low water loading with 0 and 1 water molecules. This can be understood by the fact that at low water loading, water completes the $\mathrm{Fe}$ coordination sphere. For increasing water coverage, the monodentates become more stable and water molecules are physisorbed around the adsorbed phthalates, playing a secondary solvation role for the adsorbed phthalates.

These DFT calculations confirm the possibility of protonation of $\mathrm{COO}^{-}$to $\mathrm{COOH}$ of phthalates adsorbed on the goethite surface with low water coverage. As a consequence, one of the carboxylate groups of the adsorbate can desorb and stay in a desorbed state and such a transformation is observed through the study of the different IR bands shown in the experimental part of this paper. The computational results obtained here are in good agreement with the experimental data with somewhat a better resolution of the phenomenon by adding water molecules one by one, which cannot be done with this experimental setup. The results provided by geometry optimization do not directly reproduce the spectroscopic trends but support the interpretation of experimental results.

\section{Conclusion}

By using IR spectroscopy combined with QCM and RH control system, we have been able to examine effects of a hydration/dehydration cycle on the speciation of phthalate ions adsorbed on goethite surface.

At low RH conditions, only small amounts of (ice-like) water are adsorbed on goethite surface and phthalates are considered to be adsorbed as bidentate by two carboxyl groups $\left(\mathrm{COO}^{-}\right)$bound to the goethite surface. With increasing RH, water molecules are increasingly adsorbed and parts of carboxyl groups adsorbed on the goethite can be protonated to $\mathrm{COOH}$ by accepting protons from water molecules. The phthalates are still kept adsorbed by another carboxyl groups bound to the goethite surface. At high RHs, liquid-like water molecules are abundant at the goethite surface and some of protonated carboxyls can be deprotonated and solvated in water to form $\mathrm{COO}^{-}$.

In order to test the above adsorption models based on experimental results, DFT simulations have been performed by adding 0 to 5 molecules of water to the goethite (001)/phthalate system. With low water coverage, water molecules participate in the coordination sphere of Fe with phthalates with bidentate more stable. At higher water coverage, monodentate becomes stable leading to partial desorption of phthalates. These DFT results support the above adsorption models.

These conclusions of this work can be a starting point for other environmentally and industrially relevant systems, such as the mobility of pollutants in geosphere during hydration/dehydration cycle, or for catalysts prepared by impregnation of dissolved precursors. 
R.Botella has been supported by the International Research Fellowship of Japan Society for the Promotion of Science (Postdoctoral Fellowships for Research in Japan (Summer Program)) at Osaka University. This work was granted access to the HPC resources of CINES under the allocation A0080802217 contributed by GENCI (Grand Equipement National de Calcul Intensif).

\section{Bibliography:}

[1] Kaiser, M.; Kleber, M.; Berhe, A., A. Soil Biol. Biochem. 2015, 80, 324-340

[2] Bourikas, K.; Kordulic, C.; Lycourghiotis, A. Catal. Rev. 2006, 48, 363-444

[3] Brinker, C., J. MRS Bulletin 2004, 29, 631-640

[4] Clausen, L.; Fabricius, I. J. Environ. Qual. 2001, 30, 858-869

[5] Nilsson, N.; Persson, P.; Lövgren, L.; Sjöberg, S. Geochim. Cosmochim. Acta 1996, 60, 4385-4395

[6] McBride, M., B.; Wesselink, L., G. Environ. Sci. Technol. 1988, 22, 703-708

[7] Maiti, E.; Öhman, L., O.; Nordin, J.; Sjöberg, S. J. Colloid Interface Sci. 1995, 175, 230-238

[8] Wozniewski, T.; Malinowski, S. J. Colloid Interface Sci. 1980, 77, 466-471

[9] Kishi, K.; Ikeda, S. Surf. Sci. 1980, 5, 7-20

[10] Ramstetter, A.; Baerns, M. J. Catal. 1988, 109, 303-313

[11] Kania, W.; Jurczyk, K.; Foltynowicz, Z. Surf. Technol. 1983, 18, 349-358

[12] Le Bahers, T.; Pauporté, T.; Labat, F.; Lefèvre, G.; Ciofini, I. Langmuir 2011, 27, 3442-3450

[13] G., Lefèvre, T., Preocanin, J., Lützenkirchen 2012. Infrared Spectroscopy Vol.1, T. Theophanides (ed.), Intech, pp. 97-122

[14] Hwang, Y., S.; Liu, J.; Lenhart, J., J.; Hadad, C., M. J. Colloid. Interface Sci. 2007, 307, 124-134

[15] Yang, Y.; Du, J.; Jing, C. Colloids Surf. A 2014, 441, 504-509

[16] Hanna, K.; Martin, S.; Quilès, F.; Boily, J.-F. Langmuir 2014, 30, 6800-6807

[17] Dobson, K., D.; McQuillan, A., J. Spectrochim. Acta A 1999, 55, 1395-1405

[18] Rosenqvist, J.; Axe, K.; Sjöberg, S.; Persson, P. Colloids Surf. A 2003, 220, 91-104

[19] Trout, C., C.; Kubicki, J., D. J. Phys. Chem. A 2004, 108, 11580-11590

[20] Yesilbas, M.; Boily, J.-F. J. Phys. Chem. Lett. 2016, 7, 2849-2855

[21] Asay, D., B.; Kim, S., H. J. Phys. Chem. B 2005, 109, 16760-16763

[22] Mercury, L.; Nakashima, S. Cheminform 2006, 37, 19-44

[23] Warring, S., L.; Beattie, D., A.; McQUillan, A., J. Langmuir 2016, 32, 1568-1576

[24] Dol Hamid, R.; Miskelly, G., M.; Mat Hadzir, N.; Hanapi, N., S., M.; Swellund, P., J. Appl. Geochem. 2018, 91, 89-95

[25] Hug, S., J. J. Colloid. Interface Sci. 1997, 188, 415-422

[26] Parfitt, R., L.; Smart, R., C. Soil Sci. Am. J. 1978, 42, 48-50

[27] Persson, P.; Lövgren, L. Geochim. Cosmochim. Acta 1996, 60, 2789-2799

[28] Kang, S.; Amarasiriwardena, D.; Xing, B. Colloids Surf. 2008, 75, 4846-4856

[29] Kang, S.; Xing, B. Langmuir 2007, 23, 7024-7031

[30] Rubasinghege, G.; Ogden, S.; Baltrusaitis, J.; Grassian, V. H. J. Phys. Chem. A 2013, 117, 1131611327

[31] Prasad, B. Environ. Sci.-Proc. Imp. 2021, 23, 389-399

[32] Das, M., T. ; Kumar, S., S.; Ghosh, P.; Shah, G.; Maylan, S., K.; Bajar, S.; Thakur, I., S.; Singh, L. J. Hazard. Mater. 2021, 409, 124496-

[33] Nakaya, Y.; Nakashima, S.; Otsuka, T. Appl. Spectrosc. 2021, doi: 10.1177/0003702821991219

[34] Nakaya, Y.; Okada, K.; Ikuno, Y.; Nakashima, S. e.-J. Surf. Sci. Nanotechnol. 2018, 16, 411-418

[35] Nakaya, Y.; Nakashima, S.; Otsuka, T. Geochem. J. 2019, 53, 107-414

[36] Schwertmann, U., Cornell, R., M. 2000. Iron oxides in the laboratory: preparation and characterization $2^{\text {nd }}$ ed.: p. 188

[37] Otsuka, T.; Nakasima, S. J. Miner. Petrol. Sci. 2007, 102, 302-305

[38] Nakaya, Y.; Nakashima, S.; Otsuka, T. Appl. Spectrosc. 2021, DOI: 10.1177/0003702821991219

[39] Nakaya, Y.; Okada, K.; Ikuno, Y.; Nakashima, S. e.-J. Surf. Sci. Nanotechnol. 2018, 16, 411-418 
[40] Kudo, S.; Ogawa, H.; Yamakita, E.; Watanabe, S.; Suzuki, T.; Nakashima, S. Appl. Spectrosc. 2017, 71, 1621-1632

[41] Kudo, S. and Nakashima S., 2018. "Water Adsorption with Relative Humidity Changes for Keratin and Collagen as Studied by Infrared (IR) Micro-spectroscopy". Skin Res. Technol. DOI: $10.1111 /$ srt.12641

[42] Perdew, J. P.; Burke, K.; Ernzerhof, M. Phys. Rev. Lett. 1996, 77, 3865-3868

[43] Kresse, G.; Hafner, J. Phys. Rev. B 1994, 49, 14251-14269

[44] Kresse, G.; Joubert, D. Phys. Rev. B 1999, 59, 1758-1775

[45] Kubicki, J. D.; Paul, K. W.; Sparks, D. L. Geochem. Trans. 2008, 9, 4

[46] Otte K., Schmahl W. W., Pentcheva R. Surf. Sci., 2012, 606, 1623-1632

[47] Alexandrov, V.; Rosso, K. M. Phys. Chem. Chem. Phys. 2015, 17, 14518-14531

[48] Ohno, T.; Kubicki, J. D. Phys. Chem. A 2020, 124, 3249-3260

[49] Paul, K. W.; Kubicki, J. D.; Sparks, D. L. Eur. J. Soil Sci. 2007, 58 (4), 978-988

[50] Otte, K.; Schmahl, W. W.; Pentcheva, R. J. Phys. Chem. C 2013, 117, 15571-15582

[51] Grimme, S. J. Comput. Chem. 2006, 27, 1787-1799

[52] Cornell, R. M.; Schwertmann, U. 2003 The iron oxides: structure, properties, reactions, occurrences and uses, 2nd ed.; Wiley-VCH:Weinheim,

[53]Nagano, T.; Nakashima, S.; Nakayama, S.; Osada, K.; Senoo, M. Clay Clay Miner. 1992, 40, 600607

[54] Liu, H.; Chen, T.; Qing, C.; Xie, Q.; Frost, R., L. Spectrochim. Acta A 2013, 116, 154-159

[55] Falk, M. Spectrochim. Acta 1984, 1, 43-48

[56] Zhuang, H.; Lu, P.; Lim, S., P.; Lee, H.,P. Langmuir 2008, 24, 8373-8378

[57] Ewing, G., E. J. Phys. Chem. B 2004, 108, 15953-15961

[58] Colombo, L.; Volovsek, V.; LePostollec, M. J. Raman Spectrosc. 1984, 15, 252-256

[59] Persson, P.; Nordin, J.; Rosenqvist, J.; Lövgren, L.; Öhman, L.-O.; Sjöberg, S. J. Colloid. Interface Sci. 1998, 206, 252-266

[60] Florio, G.; Zwier, T., S.; Myshakin, E., M.; Jordan, K., D.; Sibert, E., L. J. Chem. Phys. 2003, $118,1735-1746$ 